\title{
Uso da MCDA na identificação e mensuração da performance dos critérios para a certificação dos hospitais de ensino no âmbito do SUS
}

\author{
André Andrade Longaraya*, Leonardo Ensslin ${ }^{\mathrm{b}}$ \\ a*longaray@yahoo.com.br, FURG, Brasil \\ bleonardoensslin@gmail.com, UFSC, Brasil
}

\begin{abstract}
Resumo
O sistema de gestão da saúde pública brasileira passou por um processo de reestruturação nos últimos anos. Uma das consequências foi o estabelecimento de nova relação entre o Ministério da Saúde (MS) e o Ministério da Educação (MEC) no que tange ao financiamento dos hospitais universitários das universidades federais. Nesse sentido, o Ministério da Saúde implementou o processo de certificação dos hospitais universitários - um conjunto de metas a serem atingidas nos processos financeiro, de gestão e educação, bem como do modelo assistencial a ser seguido. Este artigo apresenta um método de análise de decisão multicritério aplicado no desenvolvimento de um modelo para auxiliar gestores de hospitais universitários a avaliarem o desempenho institucional no atendimento das metas pactuadas com o MS/MEC para a certificação. 0 estudo de caso foi realizado em um hospital da rede federal de educação do Brasil.
\end{abstract}

Palavras-chave

Análise de decisão multicritério. Saúde pública. Hospitais universitários.

\section{Introdução}

No Brasil, há muito tempo os hospitais vinculados às universidades federais - hospitais universitários deixaram de ter como missão prioritária a formação de novos profissionais da área de saúde. Contingências econômicas e sociais têm redirecionado o foco dessas instituições para o assistencialismo. Referência em qualidade, os hospitais universitários têm respondido por grande parte do atendimento a pacientes oriundos do Sistema Único de Saúde.

Atualmente, um hospital universitário não depende mais apenas da cota do orçamento destinado pelo Ministério da Educação à instituição pública de ensino superior a que está vinculado. Necessita também do financiamento por parte do Ministério de Saúde. Com o aumento exponencial da demanda por atendimento via SUS, as políticas de repasse orçamentário necessitaram serem revistas buscando-se uma readequação ao cenário agora vigente.

Para isso, o governo federal instituiu uma comissão interministerial para definir as alterações necessárias no processo de gerenciamento dos hospitais universitários, com o propósito de adequá-los ao novo modelo de saúde pública brasileira.

Foram diagnosticadas necessidades não só de natureza financeira, mas também de planejamento, de ensino e assistenciais. 0 relatório final da comissão sugeriu uma série de modificações nas normas de aprovação e liberação orçamentária dos recursos do Sistema Único de Saúde (SUS) para os hospitais universitários das universidades federais.

Ficou definida a obrigatoriedade da certificação dos hospitais universitários junto ao SUS, para a manutenção do repasse anual de recursos financeiros advindos do Ministério da Saúde. Foi elencado também um conjunto de sete grandes áreas a serem avaliadas para a obtenção ou renovação dessa certificação: 1) atenção à saúde; 2) políticas prioritárias para o SUS; 3) atividades de aprimoramento e aperfeiçoamento da gestão hospitalar; 4) educação; 5) pesquisa; 6) avaliação e incorporação tecnológica; e 7) financiamento. 
Os critérios específicos para cada uma das sete grandes áreas, entretanto, não foram integralmente detalhados pelo órgão gestor de saúde. Dadas as particularidades de cada hospital universitário, como seu tamanho, região onde está localizado, população a ser atendida, existência de programa de pós-graduação strictu senso etc., coube a cada um deles apresentar quais ações poderiam ser desenvolvidas para a contemplação das metas gerais de certificação.

Nesse sentido, a inexistência de um modelo científico que especifique tais metas faz com que os decisores não tenham claro quais critérios devem ser avaliados no processo de certificação. Por se tratar de um programa de médio prazo, que inclui a necessidade da reanálise periódica a fim da manutenção da certificação, um dos maiores desafios está relacionado ao desenvolvimento de um instrumento que permita a avaliação sistemática de desempenho do hospital universitário no atendimento dessas metas.

Dentro desse contexto, apresenta-se aqui o uso da metodologia multicritério de apoio à decisão (MCDA) no desenvolvimento de um modelo personalizado de avaliação de desempenho para auxiliar os gestores de um hospital universitário da rede federal de educação brasileira na identificação, operacionalização e mensuração de critérios que contemplem as metas pactuadas com o MS/SUS para a obtenção ou renovação da certificação junto a esse Ministério.

Este artigo está organizado em seis seções. Estabelecido o marco introdutório, a seção 2 discorre sobre o processo de certificação dos hospitais universitários junto ao SUS. A seção 3 expõe a base teórica que fundamenta a pesquisa. Na sequência, a seção 4 apresenta os aspectos metodológicos do trabalho. A seção 5 descreve a construção do modelo de avaliação do caso em questão. Por fim, a seção 6 tece os resultados e as considerações finais da pesquisa.

\section{O Sistema Único de Saúde e o processo de certificação dos hospitais universitários}

O Sistema Único de Saúde (SUS) foi instituído por meio da Constituição Federal de 1988 (BRASIL, 1988) e regulamentado pelas leis n. 8.080/90 e n. 8.142/90 com o objetivo de modificar a situação de desigualdade na assistência à saúde da população, tornando obrigatório o atendimento público a qualquer pessoa, sendo proibidas cobranças de valores monetários sob quaisquer pretextos (BRASIL, 1990).

A rede SUS é integrada pelos centros e postos de saúde, hospitais, incluindo os hospitais universitários, laboratórios, fundações e institutos de pesquisas médicas, bem como os hemocentros e bancos de sangue.
Com a criação do SUS, todos os cidadãos passaram a ter direito a consultas, exames, internações e tratamentos nas unidades de saúde vinculadas ao sistema, nas esferas municipal, estadual e federal, sejam essas unidades públicas ou privadas, contratadas pelo gestor público de saúde.

No que tange especificamente aos hospitais universitários, a resolução MS/MEC n. 562, de 12 de março de 2003 (BRASIL, 2003), designou uma comissão interinstitucional com o objetivo de estabelecer as bases de relacionamento entre o SUS e os hospitais de ensino (denominação adotada pelo SUS a partir dessa resolução para referir-se aos hospitais universitários).

Os trabalhos da comissão interinstitucional resultaram na criação da portaria interministerial MEC/ SUS n. 1.000, de 15 de abril de 2004 (BRASIL, 2004a), que estabeleceu os primeiros critérios para obtenção da certificação dos hospitais universitários como hospitais de ensino junto ao SUS. Complementarmente, a portaria interministerial MEC/SUS n. 1.005, de 27 de maio de 2004 (BRASIL, 2004b), definiu os documentos de verificação dos requisitos estabelecidos na portaria $n$. 1.000 , bem como instituiu a comissão de certificação de hospitais de ensino, responsável pelas visitas in loco (BRASIL, 2004a).

Na sequência, a portaria GM/MS n. 1.702, de 17 de agosto de 2004 (BRASIL, 2004c), criou o programa de reestruturação dos hospitais de ensino no âmbito do Sistema Único de Saúde; a portaria GM/MS n. 1.703, de 17 de agosto de 2004 (BRASIL, 2004d), destinou recursos de incentivo à contratualização de hospitais de ensino públicos e privados; e, a portaria GM/MS n. 2.352, de 26 de outubro de 2004 (BRASIL, 2004e), regulamentou a alocação de recursos financeiros destinados ao processo de contratualização entre o SUS e os hospitais de ensino.

Em sua essência, as portarias enfatizam o processo de contratualização entre os representantes legais dos hospitais de ensino e os gestores locais do SUS e a necessidade do atendimento de metas nas áreas de: atenção à saúde; políticas prioritárias para o SUS; atividades de aprimoramento e aperfeiçoamento da gestão hospitalar; educação; pesquisa; avaliação e incorporação tecnológica; e financiamento.

0 repasse de recursos do SUS para os hospitais de ensino passou, então, a ficar condicionado ao atendimento dessas metas.

Embora as portarias apresentem alguns índices quantitativos a serem alcançados em áreas como atenção à saúde (número de leitos destinados a pacientes SUS, percentual de atendimentos) e educação (número de residentes/ano), não contemplam, entretanto, a descrição de indicadores que permitissem 
avaliar o desempenho dos hospitais de ensino em metas relacionadas à gestão.

Nesse sentido, e diante das dificuldades encontradas pelo SUS e pelos hospitais de ensino para formalizar os processos de contratualização, principalmente no que se referia aos aspectos atinentes à operacionalização e avaliação do modelo de gestão, uma nova comissão interinstitucional foi estabelecida por meio da portaria GM/MS n. 2.988, de 22 de novembro 2006 (BRASIL, 2006), com o fim de avaliar e diagnosticar a situação dos hospitais universitários no Brasil, visando reorientar e/ou formular a política nacional para o setor.

Os trabalhos da nova comissão levaram à publicação da portaria MEC/MS n. 2.400, de 2 de outubro de 2007 (BRASIL, 2007). Ela esclareceu alguns pontos que não detalhados nas portarias anteriores, como as condicionantes da caracterização das unidades hospitalares como hospital de ensino e sobre os prazos de validade da certificação. No que tange aos indicadores de desempenho, a portaria estabeleceu em seu artigo sétimo os seguintes requisitos para obtenção da certificação dos hospitais de ensino junto ao SUS:

1 - abrigar em regime de internato acadêmicos do curso de Medicina e proporcionar atividades curriculares para acadêmicos de pelo menos outros dois cursos; 11 - abrigar em caráter permanente e contínuo programas de residência médica; 111 - garantir acompanhamento diário por docente ou preceptor para os estudantes de graduação e para os residentes, de acordo com a legislação vigente para a avaliação das condições de ensino e da Residência Médica; IV - dispor de projeto institucional próprio da IES para o desenvolvimento de atividades regulares de pesquisa científica; $\mathrm{V}$ - dispor de mecanismos de gerenciamento das atividades de ensino e pesquisa desenvolvidas no âmbito do hospital; VI - dispor de instalações adequadas ao ensino; VII - ter acesso a biblioteca atualizada e especializada na área médica; VIIl - ter as comissões assessoras obrigatórias pertinentes a instituições hospitalares constituídas; IX - desenvolver atividades de vigilância nas áreas epidemiológica, hemovigilância, farmacovigilância, tecnovigilância em saúde, vigilância em saúde do trabalhador e padronização dos medicamentos; X - dispor de programa de capacitação profissional; $\mathrm{XI}$ - participar de políticas prioritárias para o SUS; XII - dedicar um mínimo de 60\% da totalidade de leitos ativos e do total dos procedimentos praticados ao SUS, devendo atingir 100\% em no máximo dois anos a partir da contratualização; XIII - regular os serviços conveniados de acordo com as normas operativas do SUS; XIV - estar formalmente inserido no Sistema de Urgência e Emergência locorregional;
XV - ter ações compatíveis com a política nacional de humanização do SUS; XVI - garantir mecanismos de participação e controle social no hospital, com representação docente, discente, de funcionários e usuários; e XVII - comprovar sua inclusão em programa de qualificação da gestão que cumpra o disposto pelo Ministério da Saúde e pelo SUS.

A portaria destaca, ainda, que desses 17 requisitos, os de número 1,11 e XIl são imprescindíveis para desencadear o processo de avaliação para a obtenção da certificação.

Uma análise das condições estabelecidas pela portaria n. 2.400 permite tecer algumas considerações (BRASIL, 2007).

A primeira delas diz respeito à reedição de incisos de portarias anteriores. Os requisitos $1, \mathrm{ll}, \mathrm{lll}, \mathrm{IV}, \mathrm{Vll}$, $\mathrm{VIII}, \mathrm{X}, \mathrm{Xl}, \mathrm{XIl}, \mathrm{XIV}$ e XVI foram reeditados da portaria n. 1.000, de 15 de abril de 2004 (BRASIL, 2004a). 0 atendimento de alguns desses incisos já havia sido objeto de discussão e dúvidas por parte dos gestores dos hospitais de ensino em sua primeira edição.

0 fato de que apenas os requisitos 11 e XII da portaria explicitam uma relação quantitativa direta com os resultados esperados também é motivo de ponderação. 0 requisito 11 , que se refere ao número de residentes, possui um descritor que o detalha no ANEXO 111 da referida portaria. 0 requisito XII estabelece como percentual mínimo de leitos destinados ao SUS 60\% sobre o total.

Por outro lado, a maior parte dos requisitos voltados ao modelo de gestão não são detalhados. Dentre esses, destacam-se a criação de mecanismos de avaliação das atividades atinentes aos projetos institucionais de pesquisa e avaliação de tecnologias (requisito IV); o uso de medidas de gerenciamento das atividades de ensino e pesquisa (requisito V); a disponibilização de programas de capacitação profissional (requisito X); a participação efetiva em políticas prioritárias para o SUS (requisito XI); e a inserção em programas de qualificação da gestão (requisito XVII).

Outro aspecto a ser considerado é que, embora não especificado na portaria n. 2.400 (BRASIL, 2007), todos os requisitos de seu artigo sétimo fazem parte das áreas preconizadas pelo SUS: de atenção à saúde; políticas prioritárias para o SUS; atividades de aprimoramento e aperfeiçoamento da gestão hospitalar; educação; pesquisa; avaliação e incorporação tecnológica; e financiamento. Seria conveniente que os incisos estivessem agregados dentro das áreas de interesse comum.

Diante dessa análise, é possível inferir que a responsabilidade pelo desenvolvimento de instrumentos que viabilizem a mensuração, a avaliação e o 
acompanhamento da performance dos requisitos fica delegada aos gestores dos hospitais de ensino.

A complexidade que reveste essa tarefa tem suscitado uma diversidade de reflexões. Os trabalhos de Machado e Kuchenbecker (2007), Vecina Neto e Malik (2007), Costa, Mota e Figueiredo (2009), bem como do Ministério da Saúde (BRASIL, 2010), apresentam relevante discussão sobre as perspectivas nos novos modelos de gestão, ensino e assistência adotados pelos hospitais universitários frente às mudanças decorrentes do processo de contratualização com o SUS.

Inserido nesse panorama, o presente artigo trata do desenvolvimento de um modelo de avaliação de desempenho para auxiliar os gestores de um hospital universitário da rede federal de educação superior na identificação, operacionalização e mensuração dos indicadores para a obtenção da certificação junto ao SUS tendo como instrumento de intervenção a metodologia multicritério de apoio à decisão.

\section{Fundamentação teórica}

Conforme Roy (1996), a Multi Criteria Decision Aid (MCDA) insere-se entre as metodologias de decisão que empregam métodos multicritérios lastreados na abordagem de subordinação de síntese para agregação matemática dos critérios do modelo (KEENEY; RAIFFA, 1993) e assume o construtivismo como paradigma norteador do processo de apoio à decisão (BANA e COSTA, 1993).

0 processo de intervenção da MCDA é operacionalizado de forma sistêmica e sistemática por meio de três fases consequentes e interagentes entre elas: a fase de estruturação; a fase de avaliação; e a fase de recomendações. A Figura 1 ilustra todas as três fases da MCDA e as etapas que compõem cada uma delas.

$\mathrm{Na}$ primeira fase, a de estruturação, importa o entendimento do problema (Bana e Costa et al., 1999). Sob a premissa do construtivismo, procura-se identificar, caracterizar e organizar os fatos considerados relevantes no processo de apoio à decisão por meio da elaboração de uma estrutura (um modelo mais ou menos formalizado) que os intervenientes no processo devem partilhar. Na busca pela promoção do conhecimento e envolvimento dos decisores, abordagens soft de estruturação da pesquisa operacional (ROSENHEAD, 1989; CORREA, 1996; LONGARAY, 2004) como a Cognitive Mapping (EDEN, 1988) ou a Soft Systems Methodology (CHECKLAND; SCHOLES, 1999) podem ser empregadas nessa fase. Após esse procedimento, é elaborada uma estrutura hierárquica representativa dos julgamentos de valor do decisor (KEENEY, 1992). Na sequência, procede-se à construção de escalas ordinais de mensuração dos critérios e subcritérios do modelo.

Quanto à fase de avaliação, Bana e Costa (1993) explicitam que consiste em esclarecer a escolha, recorrendo à aplicação de métodos matemáticos para apoiar a modelização das preferências dos decisores e sua agregação. Isso significa dar condições ao decisor de fazer uma escolha entre ações que tenham consequências mensuráveis, segundo os diversos critérios. Fazendo uso da abordagem de subordinação de síntese, a fase de avaliação da MCDA é dividida nas etapas de construção da escala de preferência local dos critérios, de determinação das taxas de

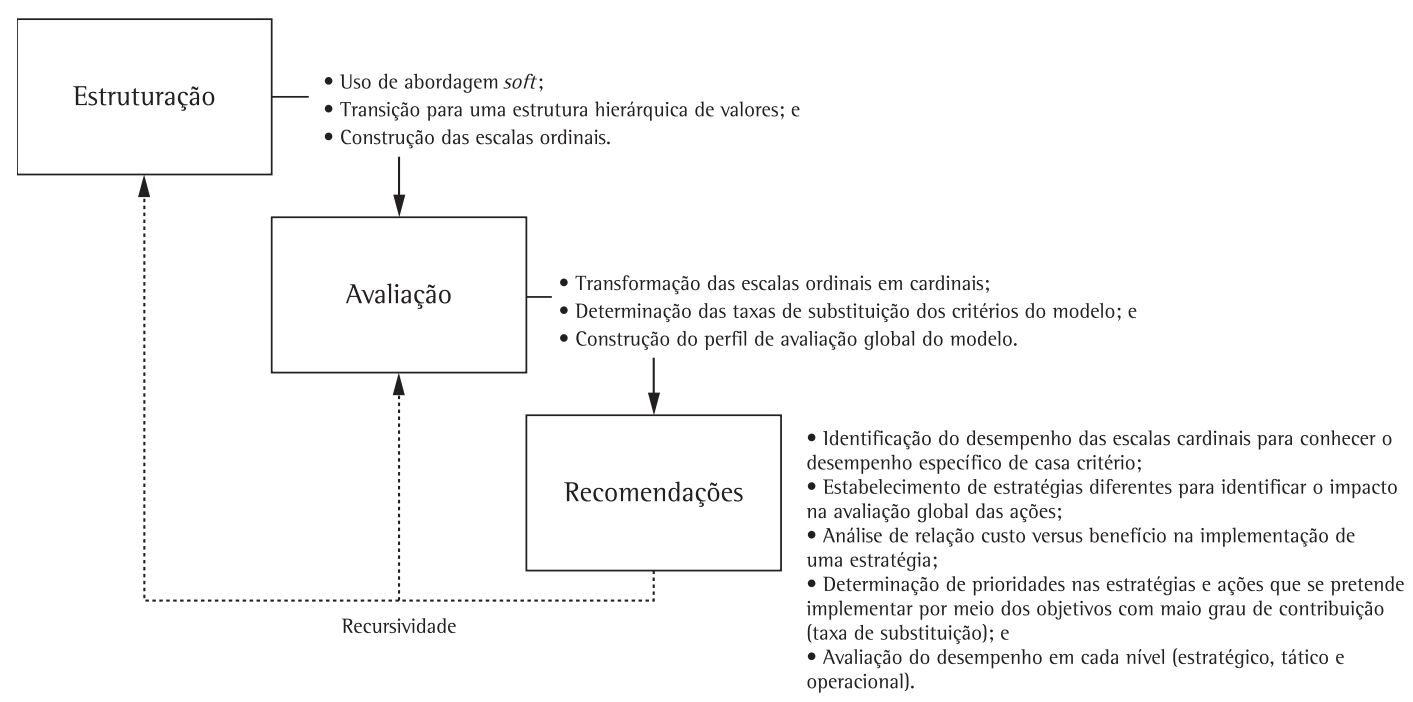

Figura 1. As fases da MCDA. Fonte: elaborada pelos autores. 
compensação entre critérios e de identificação do perfil de desempenho das ações potenciais.

Na última fase da MCDA procede-se à elaboração das recomendações. Nessa fase, objetiva-se estabelecer possíveis ações que venham ajudar o decisor a melhorar o desempenho do objeto que está sendo avaliado. Essas ações são específicas e particulares em cada caso. Elas surgem da análise dos perfis de desempenho, que procura identificar critérios nos quais o decisor deseja aperfeiçoar a performance. A análise de sensibilidade poderá ser realizada sempre que se desejar testar as consequências de uma eventual variação nos parâmetros do modelo (KEENEY; RAIFFA, 1993). Da mesma forma que as duas fases anteriores, a fase de elaboração das recomendações não tem caráter prescritivista. Isso significa que tanto as recomendações finais quanto as surgidas no decorrer do processo originam-se do aprendizado que emerge da compreensão do contexto decisório.

\section{Procedimentos metodológicos}

Esta seção descreve os procedimentos metodológicos adotados no desenvolvimento deste trabalho quanto à sua finalidade, sua natureza, a fonte de coleta de dados, a lógica de pesquisa, a abordagem metodológica e o instrumento de intervenção empregado.

Quanto à sua finalidade, a presente pesquisa se caracteriza como um estudo exploratório. Conforme Triviños (1995, p. 109), estudos exploratórios "permitem ao investigador aumentar sua experiência em torno de determinado problema”. Baseado em uma hipótese, o pesquisador aprofunda seu estudo nos limites de uma realidade específica, buscando antecedentes e um maior conhecimento. Tal perspectiva coaduna-se com os objetivos gerais e específicos desta pesquisa, direcionada à construção de um modelo personalizado de avaliação de desempenho para um hospital universitário da rede federal de educação brasileira, doravante denominado simplesmente $\mathrm{HU}$, com o intuito de identificar, operacionalizar e mensurar ações que atendam ao conjunto das metas estabelecidas pelo MS/SUS para a obtenção da certificação.

No que tange à sua natureza, esta pesquisa pode ser classificada como um estudo de caso. De acordo com Yin (2001), o emprego do estudo de caso possibilita a transformação de metas em ações factíveis e condizentes com a realidade na qual está inserida a organização em foco. Leva-se em consideração, principalmente a compreensão, como um todo, do assunto investigado, conduzindo ao surgimento e descoberta de relações que de outra forma não seriam estabelecidas. 0 caso descrito neste trabalho procura investigar de forma intensiva as formas pelas quais gestores de $\mathrm{HUs}$ percebem as possibilidades de traduzir as metas genéricas propostas pelo MS/SUS para a obtenção da certificação em ações específicas.

0 estudo de caso foi desenvolvido em um dos 46 hospitais universitários da rede federal de educação brasileira. Nele trabalhavam 103 docentes dos cursos de Medicina e Enfermagem, 463 técnicos em Educação, 268 funcionários de uma fundação de apoio, 40 médicos residentes e uma quantidade significativa de estagiários de diversas áreas profissionais. Formam-se em média 60 novos médicos e 50 enfermeiros por ano. Serve como campo de estágio a cursos técnicos, de graduação e pós-graduação da comunidade e região onde está localizado. $\mathrm{Na}$ área assistencial, o hospital universitário em questão atende uma população residente estimada em mais de 240 mil habitantes.

As fontes de coleta de dados foram de natureza primária e secundária. Os dados primários foram coletados diretamente junto à gestora do HU participante do processo. Dados secundários, quando necessários para subsidiar as decisões da decisora, foram obtidos de documentos da organização e também de referenciais teóricos.

Quanto à lógica de pesquisa, pode-se inferir que ela é mista. Na etapa de estruturação, a lógica é indutiva, pois nessa fase da MCDA em que são determinados os elementos primários de avaliação e elaboradas as escalas ordinais não se parte de princípios e sim dos fatos resultantes de observações e inserção na realidade (ROESCH, 2005). Já na fase de avaliação, a lógica é dedutiva, pois, a partir do modelo construído se procura estabelecer conclusões particulares (TRIVIÑOS, 1995). Na fase de recomendações, a lógica é predominantemente indutiva, pois as análises são feitas a partir do entendimento adquirido no decorrer de todo o desenvolvimento do modelo.

A abordagem metodológica empregada nesta pesquisa se caracteriza como qualitativo-quantitativa (ROESCH, 2005). Ela assume perfil qualitativo na fase de estruturação, baseada em um processo de intervenção que promove a reflexão em busca da identificação, representação e determinação dos elementos primários de avaliação e de suas interrelações na construção das escalas ordinais. Pode ser tipificada como quantitativa na fase de avaliação, quando ocorre a construção do modelo matemático multicritério, por meio da transformação das escalas ordinais em escalas cardinais, a determinação das taxas de compensação entre critérios e a identificação do perfil de desempenho das ações.

0 instrumento de intervenção selecionado para o desenvolvimento do modelo de avaliação de 
desempenho do HU para o fim específico de obtenção e renovação da certificação junto ao MS/SUS é a MCDA. A escolha desta metodologia de apoio à decisão se deve à sua capacidade de proporcionar condições de identificação, operacionalização e mensuração das ações que representam a percepção da gestora do HU quanto às possibilidades de atendimento das metas estabelecidas pelo MS/SUS. Permite, ainda, oferecer sugestões para a melhoria das ações em que o desempenho não se mostrou compatível com o desejado.

\section{Construção do modelo de avaliação de desempenho para o $\mathrm{HU}$ da rede federal de Educação}

Esta seção apresenta o detalhamento do processo de construção do modelo de avaliação de desempenho para o HU por meio da utilização da MCDA como instrumento de intervenção. Nesse sentido, as fases de estruturação, de avaliação e de recomendações são descritas na sequência.

\subsection{Estruturação do modelo}

A estruturação de um modelo MCDA observa a consecução de três etapas: o uso de uma abordagem soft da pesquisa operacional, a transição da estrutura hierárquica do modelo soft para uma estrutura hierárquica arborescente e a construção das escalas ordinais.

\subsubsection{Uso de abordagem soft da pesquisa operacional}

Na primeira etapa da fase de estruturação da MCDA, o pesquisador emprega uma das abordagens soft da pesquisa operacional para auxiliar o decisor a compreender, delimitar e organizar seu problema.

Neste trabalho, os autores utilizaram a técnica de mapas de relações meios-fins, baseada nos trabalhos de Eden (1988), mas com algumas distinções. $\mathrm{Na}$ metodologia MCDA, o mapa é uma representação gráfica que o pesquisador faz da representação discursiva sobre o problema narrado pelo decisor (ENSSLIN et al., 2010). Outra diferença diz respeito à parte gráfica. Enquanto o design dos mapas de Eden (1988) não se atém a um posicionamento ordenado dos conceitos no espaço, os mapas construídos à luz da MCDA apresentam tanto os conceitos quanto seus agrupamentos (clusters) organizados em uma aparência que facilita a visualização da hierarquia de conceitos para o observador.
Foram realizadas quatro entrevistas não estruturadas com a decisora. Nesse processo, a entrevistada foi incentivada pelos pesquisadores a discorrer sobre aspectos por ela julgados importantes em um modelo de avaliação do hospital de ensino e que representassem ações que impactariam sobre os critérios para obtenção da certificação junto ao SUS. A cada entrevista, um novo esboço do mapa era obtido.

A Figura 2 expõe, a título de ilustração, um recorte do mapa de relações meios-fins do caso em estudo em que é delineado o cluster Educação:

Com o mapa de relações meios-fins construído, cumpriu-se o objetivo do uso de uma abordagem soft na fase de estruturação da MCDA. As diversas relações de influência que emergiram na construção do mapa proporcionaram à decisora a possibilidade de explorar o contexto decisório e expandir seu entendimento sobre o problema.

\subsubsection{Transição do mapa de relações meios- fins para a estrutura hierárquica de valores}

Superada a etapa de construção do mapa de relações meios-fins, é necessário proceder à conversão da estrutura de ligações de influência oriundas do mapa em uma estrutura hierárquica arborescente para, a partir dela, ser elaborado o modelo multicritério para o caso em estudo.

Na MCDA essa transição é realizada com o auxílio da abordagem de enquadramento proposta por Keeney (1992). De acordo com Keeney (1992), realizar o enquadramento significa delinear um quadro (frame) do processo decisório no qual constem os objetivos estratégicos dos decisores projetados em pontos de vista fundamentais (PVFs) e o conjunto de todas as ações possíveis para atingir esses objetivos (ações potenciais). 0 resultado desse enquadramento é a construção da estrutura hierárquica de valores para o problema.

A Figura 3 apresenta a estrutura hierárquica de valores do estudo de caso. No nível mais alto encontra-se o rótulo do problema. 0 segundo nível descreve as áreas de preocupação (clusters) Educação, Atenção à saúde, Gestão e Humanização. 0 nível seguinte expõe os 10 PVFs do modelo.

\subsubsection{Construção das escalas ordinais (descritores)}

$\mathrm{Na}$ MCDA, o modelo multicritério deve ter condições de operacionalizar uma forma pela qual cada ponto de vista fundamental possa servir de base para a mensuração do impacto das ações e para a 


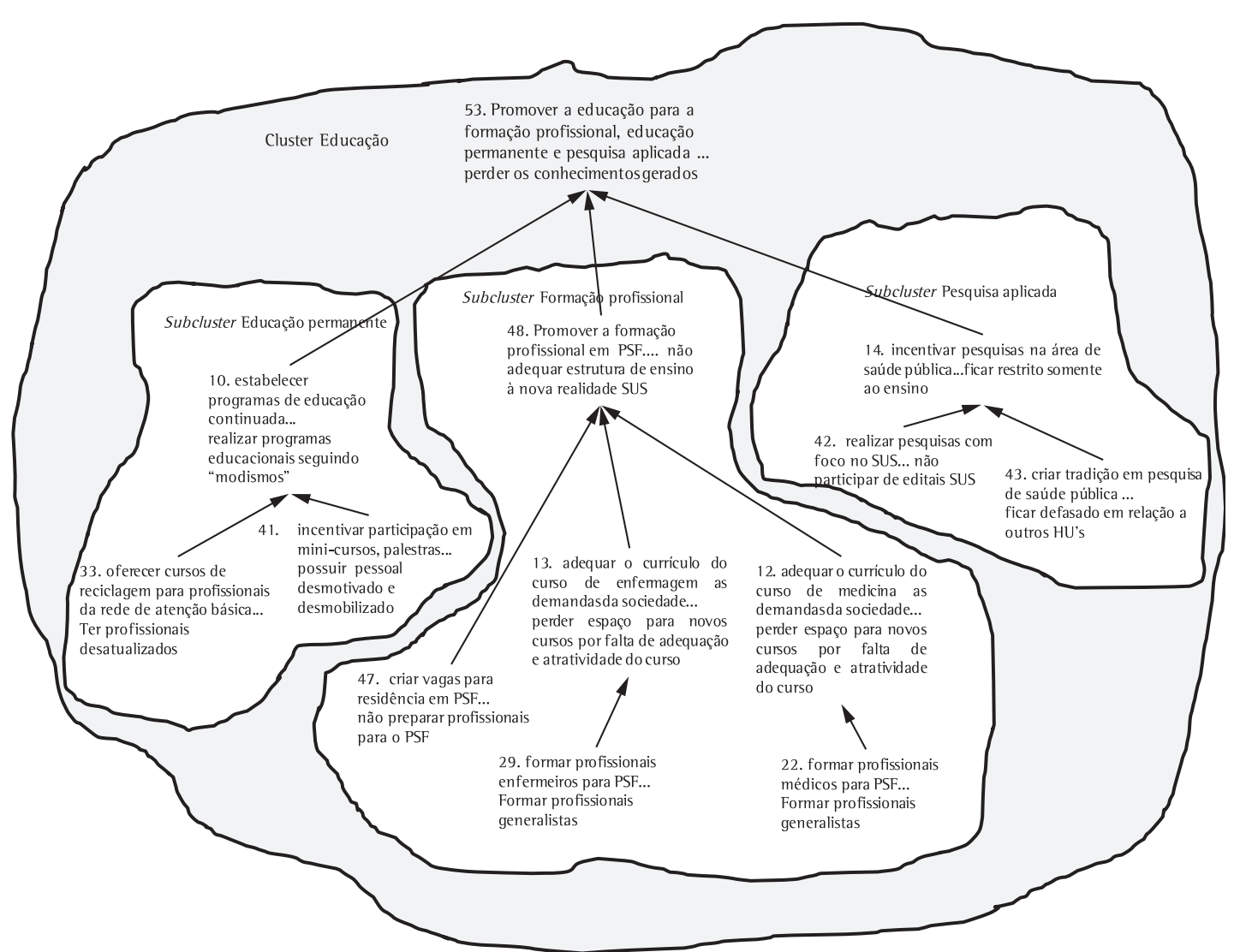

Figura 2. Recorte do mapa de relações meios-fins ilustrando o cluster Educação. Fonte: elaborada pelos autores.

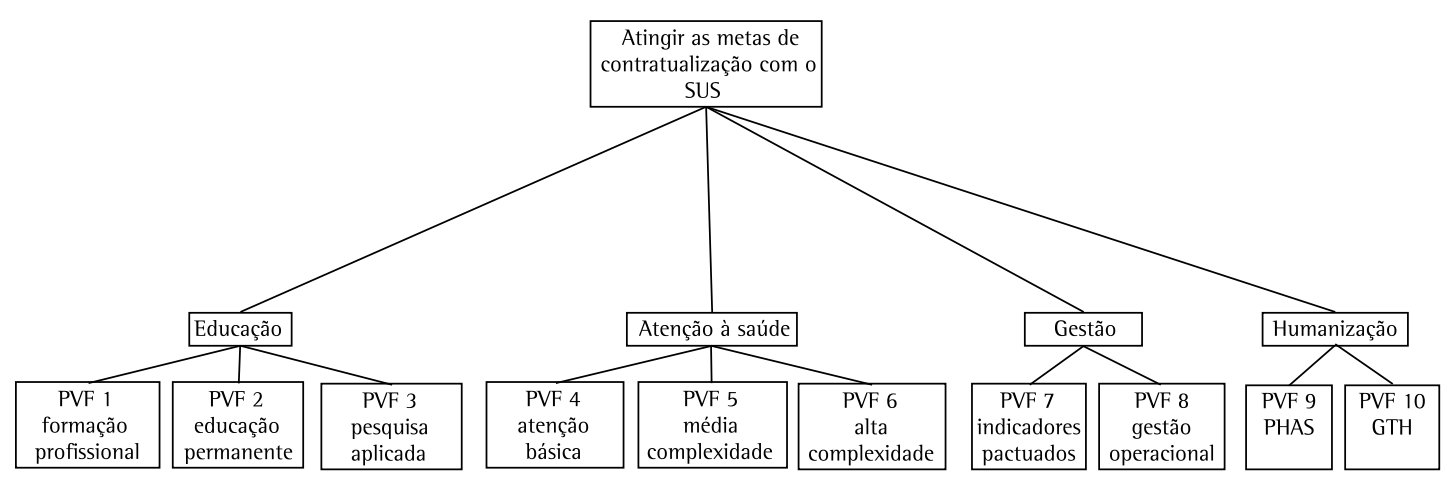

Figura 3. Estrutura hierárquica de valor. Fonte: elaborada pelos autores.

comparação das consequências relativas e absolutas dessas ações. 0 instrumento que viabiliza esse processo é chamado de descritor (KEENEY, 1992).

Um descritor é uma escala ordinal. Ela mede atributos que se distinguem em grau ou intensidade, de forma que, além das relações de igualdade/ desigualdade, podem-se reconhecer relações de ordem $(<,>)$. Possui sentido de direção definido, mas as unidades de mensuração são desconsideradas. Os descritores são escalas ordinais e, portanto escalas qualitativas, mesmo quando se valendo de símbolos numéricos, eles serão apenas símbolos alfanuméricos.

Na construção dos descritores do caso utilizou-se um processo interativo em que a decisora foi incentivada a descrever uma escala que representasse, segundo seu julgamento de valor, a intensidade e o ordenamento dos atributos de cada PVF. Para permitir a comparação entre os descritores, procedeu-se à 
ancoragem dos níveis da escala de cada descritor em nível Neutro (desempenho mínimo aceitável) e nível Bom (desempenho satisfatório). Uma ação com impacto abaixo do nível Neutro da escala apresenta desempenho comprometedor. Se o impacto estiver entre os níveis Neutro e Bom, a performance é considerada competitiva. Já um impacto acima do nível Bom representa excelência (KEENEY, 1992).

Foram construídos 32 descritores para todos os 10 PVFs do modelo. Salienta-se que durante o processo a decisora verificou a necessidade do desmembramento de alguns PVFs para facilitar seu entendimento e operacionalização. Novos aspectos identificados a partir de PVFs são denominados Pontos de Vista Elementares (PVEs). Utilizam-se PVEs quando um PVF ainda é demasiado abrangente para ser mensurado (ENSSLIN et al., 2010).

Com a conclusão da construção dos descritores para a estrutura hierárquica de valores encerra-se a fase de estruturação da MCDA. Contribui enfatizar, contudo, que, assim como as demais fases, a estruturação também é recursiva, cabendo ao pesquisador e à decisora retornarem a ela sempre que recomendações possam ser incorporadas.

\subsection{Avaliação (construção do modelo multicritério)}

Cumprida a etapa de construção das escalas ordinais, onde ficaram definidos os níveis em que se podem avaliar as ações potenciais em cada ponto de vista fundamental, o próximo passo diz respeito ao desenvolvimento de um modelo multicritério que permita mensurar essas ações, tanto local quanto globalmente. Na metodologia MCDA o processo de avaliação ocorre em três etapas: a elaboração das funções de valor, a determinação das taxas de substituição dos critérios e o desenvolvimento da avaliação global e do perfil de impacto da situação atual.

\subsubsection{Determinação das funções de valor (avaliação local do modelo)}

No primeiro passo da fase de construção do modelo multicritério deseja-se determinar uma função de valor para cada um dos pontos de vista fundamentais da estrutura hierárquica desenvolvida, tendo como referência seus descritores (BANA e COSTA; VANSNICK, 1995). Neste trabalho, optou-se pela utilização de um método de julgamento semântico. Nesse tipo de método, a função de valor é obtida através de comparações par a par da diferença de atratividade entre alternativas potenciais (BEINAT,
1995). Para isso, solicita-se ao decisor que expresse qualitativamente, através de uma escala ordinal semântica, a intensidade de preferência percebida. $\mathrm{Na}$ operacionalização desse processo foi empregado o método MACBETH - Measuring Attractiveness by a Categorical Based Evaluation Technique (BANA e COSTA; VANSNICK, 1995).

Inicialmente foi solicitado à decisora que explicitasse a diferença de atratividade por ela percebida entre as alternativas potenciais para cada um dos critérios do modelo. A decisora expôs para todas as comparações par a par formuladas a ela se a diferença era nula, muito fraca, fraca, moderada, forte, muito forte ou extrema. As respostas obtidas da decisora permitiram a elaboração das matrizes de julgamento, que serviram de subsídio para que o software M-MACBETH calculasse as funções de valor com base nos aspectos teórico-matemáticos apresentados nessa seção. Na sequência, procedeu-se à normalização das funções de valor calculadas. Depois de estimadas as escalas de intervalo, deve-se fixar para cada descritor o valor da escala referente ao nível Neutro em 0 (zero) e o valor da escala relativa ao nível Bom em 100 (cem) (BANA e COSTA; VANSNICK, 1995). Essa transformação permite ancorar a faixa de variação das funções de valor, fazendo com que o nível Bom tenha atratividade equivalente em todos os descritores, o mesmo ocorrendo com o nível Neutro (ENSSLIN; MONTIBELLER; NORONHA, 2001). 0 procedimento matemático para estabelecer a ancoragem dos níveis Neutro e Bom (em 0 e 100) dos descritores consistiu na utilização de uma transformação linear positiva do tipo $f(x)=\alpha x+\beta$ (BEINAT, 1995).

A Figura 4 ilustra o processo de transformação de uma escala ordinal (descritor) em uma escala cardinal intervalar (função de valor) para o descritor D7 - número de servidores do HU com participação em congressos, seminários, simpósios no período de um ano. São apresentadas a escala ordinal, a matriz de transformação semântica e a função de valor ancorada (escala cardinal de intervalos normalizada). Com a determinação das funções de valor para todos os descritores do problema, a decisora passou a contar com a mensuração cardinal dos aspectos operacionais de seu modelo. Tomando-se o exemplo da Figura 4, a decisora entendeu que realizar uma ação que promova no descritor D7 o acréscimo de 15 para 20 servidores do HU em congressos, seminários e simpósios irá impactar localmente em 57,14 pontos seu modelo.

Nessa etapa, entretanto, o decisor ainda não pode medir o desempenho, nem estabelecer comparações entre os objetivos estratégicos (PVFs) ou entre os objetivos táticos (PVEs) da estrutura hierárquica de 


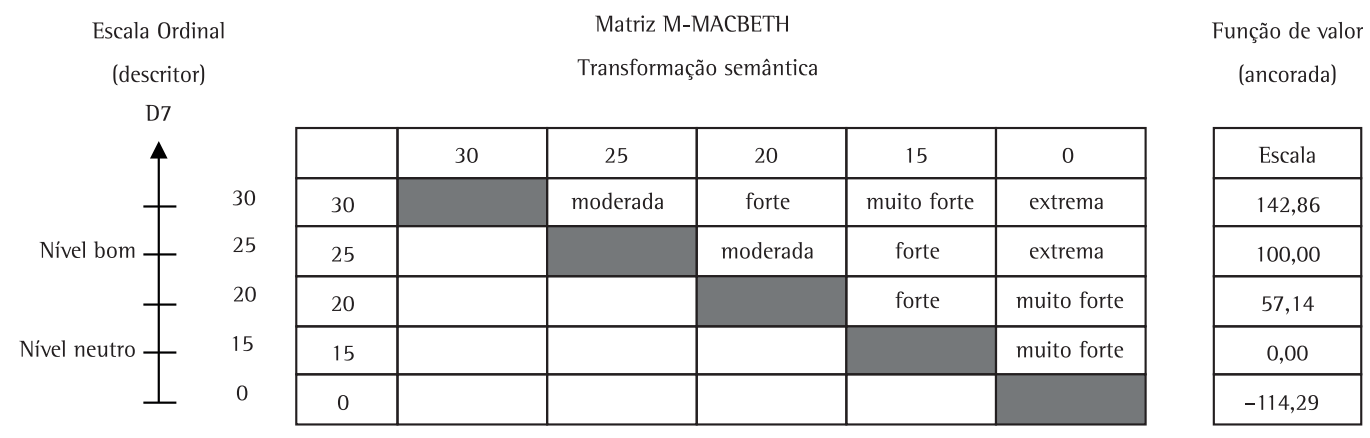

Figura 4. Transformação do descritor D7 em uma função de valor por meio do MACBETH. Fonte: elaborada pelos autores.

valores. Para que isso ocorra é necessário que se determinem as taxas de substituição e, na sequência, se proceda à agregação aditiva do modelo (avaliação global).

\subsubsection{Determinação das taxas de substituição}

Para a obtenção da agregação aditiva do modelo deve-se, preliminarmente, determinar as taxas de substituição. Na MCDA, as taxas de substituição refletem, segundo o julgamento de um decisor, a perda de desempenho que uma ação potencial deve sofrer em um PVF para compensar o ganho de desempenho em outro PVF (ROY, 1996).

Para o estabelecimento das taxas de substituição do modelo desta pesquisa foi utilizado o método de comparação par a par do MACBETH, em um procedimento similar ao empregado para a construção das funções de valor. Tal escolha deveu-se ao fato de a decisora já estar familiarizada ao uso da matriz de julgamentos semânticos e seus níveis de preferência (nula, muito fraca, fraca, moderada, forte, muito forte, extrema).

A Figura 5 ilustra o processo de obtenção das taxas de substituição. Ela permite visualizar (1) as comparações par a par, (2) a ação potencial fictícia A0, (3) a matriz de Roberts (1979) para ordenar as ações, (4) a matriz de julgamentos MACBETH e (5) a escala do software M-MACBETH ancorada com as taxas de substituição para os PVF1 - formação profissional, PVF2 - educação permanente e PVF3 - pesquisa aplicada.

Em um processo interativo com a decisora, repetiu-se o mesmo procedimento para a determinação de todas as taxas de substituição entre os PVFs e PVEs da estrutura hierárquica de valores construída para o problema. Terminada esta etapa, é possível realizar a agregação aditiva do modelo.

\subsubsection{Agregação aditiva dos critérios (avaliação global do modelo)}

0 objetivo da avaliação global é transformar um modelo que tenha múltiplos critérios em um modelo de critério único. Isso permite o cálculo da pontuação geral de uma ação potencial em relação às demais ações concorrentes. Para a avaliação global do modelo multicritério, Bana e Costa e Vansnick (1995) sugerem o uso de uma função de agregação aditiva, demonstrada a seguir por meio da Equação (1):

$V(a)=\sum_{i}^{n} V_{i}(a) \cdot w_{i}$

onde: $\mathrm{V}(\mathrm{a})$ - valor global da ação $a ; v_{i}(a)-$ valor parcial da ação a no i-ésimo critério com i $=1,2, \ldots, n ; w_{i}-$ peso ou taxa de compensação do i-ésimo critério com $\mathrm{i}=1,2, \ldots, \mathrm{n} ; \mathrm{n}$ - número de critérios do modelo.

Observando a Equação 1, depreende-se que a mesma fornece a soma ponderada dos valores parciais obtidos por uma determinada ação nos diversos PVFs, sendo que a ponderação é feita pelas taxas de compensação de cada PVF, o que viabiliza a transformação das unidades de atratividade local em unidades de atratividade global.

Para calcular os valores parciais obtidos por uma ação em um PVF isolado, tem-se a equação (2):

$$
V_{P V F k}(a)=\sum_{i=1}^{n k} W_{i, k} \cdot V_{i, k}(a)
$$

onde: $V_{\mathrm{PVFk}}(a)$ - valor global da ação $a$ do $\mathrm{PVF}_{\mathrm{k}}$, para $\mathrm{k}=1, \ldots \mathrm{m} ; v_{\mathrm{i}, \mathrm{k}}($ a) - valor parcial da ação a no critério $\mathrm{i}$, $\mathrm{i}=1, \ldots \mathrm{n}$, do $\mathrm{PVF}_{\mathrm{k}}$, para $\mathrm{k}=1, \ldots \mathrm{m}$; $a$ - nível de impacto da ação $a ; w_{\mathrm{i}, \mathrm{k}}$ - taxas de substituição do critério i, $\mathrm{i}=1, \ldots \mathrm{n}$, do $\mathrm{PVF}_{\mathrm{k}}$, para $\mathrm{k}=1, \ldots \mathrm{m} ; \mathrm{n}_{\mathrm{k}}-$ número de critérios do $\mathrm{PVF}_{\mathrm{k}}$, para $\mathrm{k}=1, \ldots \mathrm{m} ; \mathrm{m}$ - número de PVFs do modelo. 
1 Comparação par-a-par dos critérios
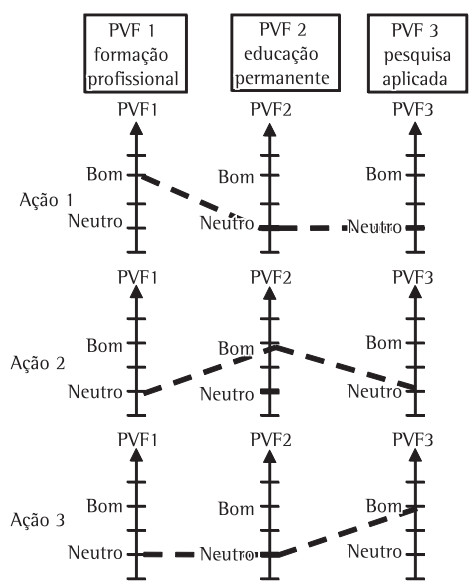

2 Inserção de uma ação potencial fictícia A0

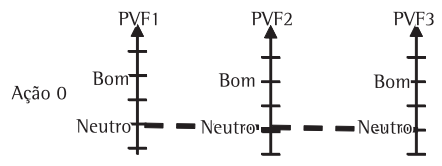

3 Matriz de ordenação de Roberts (1979)

\begin{tabular}{|l|l|l|l|l|l|l|}
\hline & A1 & A2 & A3 & A0 & soma & ordem \\
\hline A1 & & 0 & 1 & 1 & 2 & 2 \\
\hline A2 & 1 & & 1 & 1 & 3 & 1 \\
\hline A3 & 0 & 0 & & 1 & 1 & 3 \\
\hline A0 & 0 & 0 & 0 & & 0 & 4 \\
\hline
\end{tabular}

4 Matriz de julgamentos MACBETH

\begin{tabular}{|l|l|l|l|l|}
\hline & A2 & A1 & A3 & A0 \\
\hline A2 & & muito forte & muito forte & muito forte \\
\hline A1 & & & muito forte & muito forte \\
\hline A3 & & & & moderada \\
\hline A0 & & & & \\
\hline
\end{tabular}

5 Escala M -MACBETH (ancorada)

TAXAS DE SUBSTITUIÇÃO PVF1-PVF2-PVF3
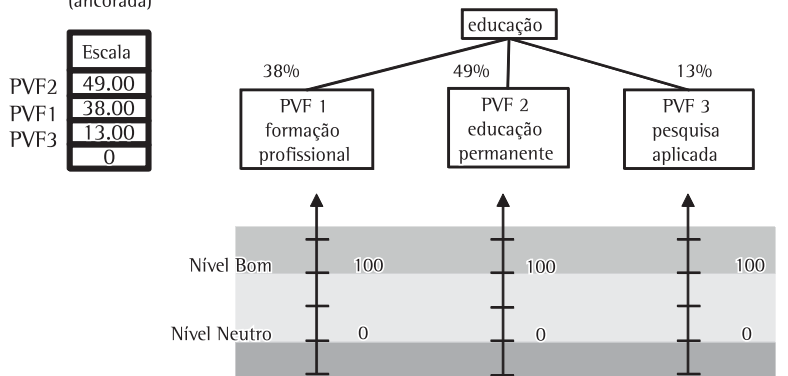

Figura 5. 0 processo de construção das taxas de substituição entre os PVF1 - formação profissional, PVF2 - educação permanente e PVF3 - pesquisa aplicada. Fonte: elaborada pelos autores.

A Figura 6 demonstra a agregação das taxas de substituição do PVF2 - educação permanente, que engloba o PVE2.1 - capacitação (composto pelos descritores D5 e D6) e o PVE2.2 - atualização (formado pelos descritores D7 e D8).

$$
\left(\begin{array}{c}
P V E 2.1 \\
54,6 \%
\end{array}\left(41,7 \%\left(\begin{array}{c}
D 5 \\
160 \\
100 \\
72,1 \\
0 \\
-40
\end{array}\right)+58,3 \%\left(\begin{array}{c}
200,2 \\
100 \\
66,8 \\
0 \\
-33,4
\end{array}\right)\right)+45,4 \%\left(66,7 \%\left(\begin{array}{c}
142,8 \\
100 \\
57,1 \\
0 \\
-114,2
\end{array}\right)+33,3 \%\left(\begin{array}{c}
D 8 \\
166 \\
100 \\
83,3 \\
0 \\
-50
\end{array}\right)\right)\right.
$$

Figura 6. Agregação parcial para o PVF2. Fonte: elaborada pelos autores

Com base na Equação 2 e empregando os dados fornecidos na Figura 6, tem-se a fórmula de agregação do PVF2 do modelo para uma determinada ação (a):

$V_{P V F 2}(a)=0,546 \cdot\left[\left(0,417 \cdot v_{D 5}(a)\right)+\left(0,583 \cdot v_{D 6}(a)\right)\right]+0,454 \cdot\left[\left(0,667 \cdot v_{D 7}(a)\right)+\left(0,333 \cdot V_{D 8}(a)\right)\right]$

0 mesmo procedimento foi executado para todos os PVFs do modelo construído para o estudo de caso.

Ainda utilizando-se a Equação 2 foi possível agregar a área de preocupação Educação da estrutura hierárquica de valores (ver Figura 3), composta do PVF1 - formação profissional, PVF2 - educação permanente e PVF3 - pesquisa aplicada.

Obteve-se assim, a fórmula de agregação para a área de preocupação Educação: 


$$
\begin{aligned}
& V_{E D U C A C ̧ \tilde{A O}}(a)=0,38 \cdot\left[\left(0,28 \cdot v_{D 1}(a)\right)+\left(0,20 \cdot v_{D 2}(a)\right)+\left(0,12 \cdot v_{D 3}(a)\right)+\left(0,40 \cdot v_{D 4}(a)\right)\right]+ \\
& \text { 0, 49. }\left\{0,546 \cdot\left[\left(0,417 \cdot v_{D 5}(a)\right)+\left(0,583 \cdot v_{D 6}(a)\right)\right]+0,454 \cdot\left[\left(0,667 \cdot v_{D 7}(a)\right)+\right.\right. \\
& \left.\left.\left(0,333 \cdot v_{D 8}(a)\right)\right]\right\}+0,13 \cdot\left[\left(0,667 \cdot v_{D 9}(a)\right)+\left(0,333 \cdot v_{D 10}(a)\right)\right]
\end{aligned}
$$

Procedendo do mesmo modo, obtiveram-se as fórmulas de agregação para as áreas de preocupação atenção à saúde, gestão e humanização:

$$
\begin{aligned}
& V_{\text {ATENCSÃO Ȧ SAÚDE }}(a)=0,444 \cdot\left\{0,667 \cdot\left[\left(0,333 \cdot v_{D 11}(a)\right)+\left(0,143 \cdot v_{D 12}(a)\right)+\left(0,286 \cdot v_{D 13}(a)\right)+\right.\right. \\
& \left.\left.\left(0,238 \cdot v_{D 14}(a)\right)\right]+0,333 \cdot\left[\left(0,625 \cdot v_{D 15}(a)\right)+\left(0,375 \cdot v_{D 16}(a)\right)\right]\right\}+0,333 \cdot\left\{0,546\left[\left(0,615 \cdot v_{D 16}(a)\right)+\right.\right. \\
& \left.\left.\left(0,385 \cdot v_{D 17}(a)\right)\right]+0,454 \cdot\left[\left(0,417 \cdot v_{D 18}(a)\right)+\left(0,583 \cdot v_{D 19}(a)\right)\right]\right\}+0,223 \cdot\left\{0,556 \cdot\left[\left(1 . v_{D 20}(a)\right)\right]+\right. \\
& \left.0,444 \cdot\left[\left(0,4 \cdot v_{D 21}(a)\right)+\left(0,6 \cdot v_{D 23}(a)\right)\right]\right\} \\
& V_{\text {GESTÃO }}(a)=0,583 \cdot\left[\left(0,375 \cdot v_{D 24}(a)\right)+\left(0,312 \cdot v_{D 25}(a)\right)+\left(0,188 \cdot v_{D 26}(a)\right)+\left(0,125 \cdot v_{D 27}(a)\right)\right]+ \\
& 0,417 \cdot\left[\left(0,40 . v_{D 28}(a)\right)+\left(0,60 . v_{D 29}(a)\right)\right] \\
& V_{\text {HUMANIZAÇÃO }}(a)=0,714 \cdot\left[\left(0,60 \cdot v_{D 30}(a)\right)+\left(0,40 \cdot v_{D 31}(a)\right)\right]+0,286 \cdot\left[\left(1 \cdot v_{D 32}(a)\right)\right]
\end{aligned}
$$

Realizadas as agregações das áreas de preocupação que englobam os PVFs, PVEs e descritores em seus níveis hierárquicos inferiores, pôde-se agregar a performance de uma ação (a) em uma performance única $\mathrm{V}(\mathrm{a})$ usando a equação da função aditiva global (1):

$$
V(a)=0,188 \cdot V_{\text {EDUCAÇ̃̃o }}(a)+0,437 \cdot V_{\text {ATENÇ̃̃o Ȧ SAÚdE }}(a)+0,063 \cdot V_{\text {GESTÃO }}(a)=0,312 \cdot V_{\text {HUMANIZAÇÃO }}(a)
$$

Desse modo, V(a) expressa a fórmula de avaliação global de desempenho para o modelo de apoio à decisão HU, onde as constantes (18,8\%, 43,7\%, 6,3\% e $31,2 \%$ ) referem-se às preferências ponderadas da decisora obtidas na comparação par a par do MACBETH em relação às áreas de preocupação. Tem-se, assim, o modelo multicritério construído.

\subsubsection{Perfil de impacto da situação atual}

Determinado o modelo de avaliação global, pode-se empregá-lo com o objetivo de medir o impacto das ações executadas na busca do atendimento das metas propostas, por meio da mensuração do perfil de impacto da situação atual.

Nessa etapa, o entendimento gerado está refletido no modelo de avaliação de desempenho, que permite identificar os aspectos onde a instituição está em nível competitivo, de excelência e comprometedor. Para ilustrar o estudo de caso, a decisora procedeu à pontuação do perfil vigente naquele momento, como demonstra a Figura 7.
A Figura 7 permite identificar a situação do HU em estudo quanto aos objetivos estratégicos para a contratualização com o SUS. No momento em que se realizava a avaliação, a decisora julgou que o PVF5 - média complexidade apresentou desempenho de excelência. Os PVF1 - formação profissional, PVF2 - educação permanente, PVF4 - atenção básica, PVF6 - alta complexidade, PVF7 - indicadores pactuados, PVF9 - PHAS e PVF10 - GTH obtiveram desempenho competitivo. O PVF3 - pesquisa aplicada e o PVF8 - gestão operacional tiveram o menor desempenho dentre todos os PVFs avaliados, impactando no nível mínimo aceitável. Não houve, contudo, a identificação de nenhum PVF com desempenho comprometedor. A pontuação obtida no modelo de avaliação global foi de 72,31 pontos. Convém esclarecer que na MCDA tal pontuação serve apenas como âncora para possíveis comparações entre diferentes perfis. Delineado o perfil de impacto do status quo, a decisora passou a contar com um instrumento que reflete seu entendimento de onde é conveniente atuar para atingir os objetivos estratégicos do modelo. 


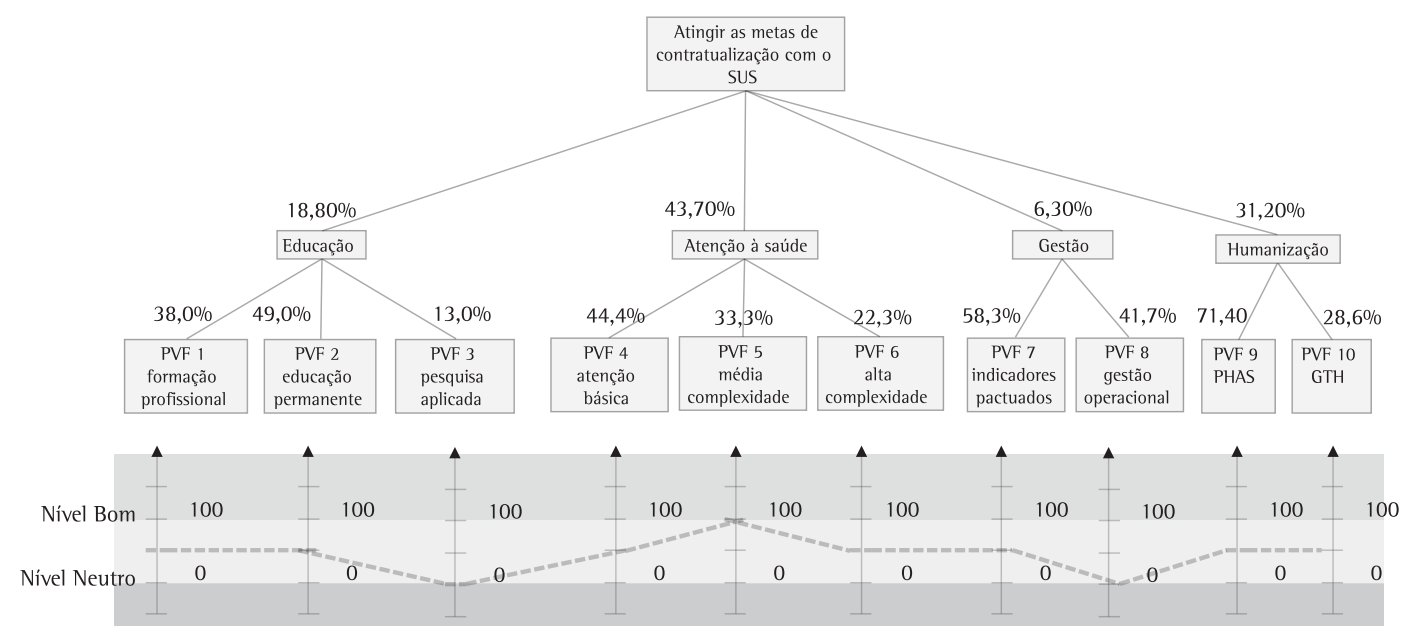

Legenda:

Perfil atual

Pontuação: 72,31

Figura 7. Perfil de impacto do status quo do HU no modelo construído. Fonte: elaborada pelos autores.

A MCDA sugere que, após a avaliação do perfil de impacto atual, proceda-se à fase de recomendações, a fim de identificar possiveis ações a serem implementadas e o impacto delas no alcance das metas propostas no modelo.

\subsection{Recomendações}

A fase de recomendações da MCDA tem por objetivo apoiar o decisor no uso do modelo global de avaliação. Não pretende prescrever orientações, mas auxiliar o decisor na construção de alternativas e compreensão de suas consequências. A operacionalização desse processo pode ser realizada de várias formas, dentre as quais se podem citar:

- Identificar o desempenho de cada escala cardinal para conhecer o desempenho específico em determinado PVF;

- Estabelecer estratégias diferentes para identificar o impacto na avaliação global de desempenho;

- Analisar a relação custo versus benefício na implementação de uma estratégia;

- Estabelecer prioridades nas estratégias e ações que se pretende implementar por meio dos objetivos com maior grau de contribuição (taxas de compensação); e

- Avaliar o desempenho em cada nível (estratégico, tático e operacional).

Para ilustrar o caso em questão, a decisora entendeu que seria importante investigar as causas do baixo desempenho do PVF3 - pesquisa aplicada e do PVF8 - gestão operacional em relação aos demais pontos de vista fundamentais do modelo no perfil de impacto do status quo.
Em uma análise descendente da estrutura hierárquica de valores, verificou-se que o PVF3 faz parte da área de preocupação educação, que tem taxa de substituição de 18,80\% (ver Figura 7), o que é uma preferência baixa em relação às áreas de preocupação atenção à saúde $(43,70 \%)$ e humanização $(31,20 \%)$. Segundo o julgamento da decisora, ela é preferível apenas em comparação à área gestão (6,30\%). No nível imediatamente abaixo do PVF3 encontram-se os descritores que o operacionalizam, o descritor D9 - número de pesquisas desenvolvidas no HU com foco no SUS e descritor D10 - número de publicações de resultados de pesquisa com foco no SUS em periódicos científicos.

De acordo com o exame das escalas cardinais, o desempenho insatisfatório do PVF3 pode ser explicado pelo baixo índice de publicações de pesquisas resultantes de projetos com ênfase na saúde pública em periódicos que estejam avaliados no Qualis da Capes. Para essa situação, a decisora entendeu ser necessária a previsão de um projeto claro de política de inserção das pesquisas do HU em editais SUS e que esse deveria constar no plano operacional do hospital para os próximos anos.

Em outra análise da estrutura hierárquica de valores do problema da decisora, constatou-se que o PVF8 - gestão operacional é parte integrante da área de preocupação gestão, a de menor importância para o modelo, segundo o julgamento da decisora (taxa de substituição de 6,30\%). Ele é composto dos descritores D28 - nível de informatização do HU (percentual de serviços e unidades informatizadas) e descritor D29 - uso de instrumentos de controle gerencial. 
No PVF8, as duas escalas cardinais (D28 e D29) obtiveram desempenho insuficiente na visão da decisora. No que tange ao nível de informatização (D28), há um número significativo de sistemas de processamento transacionais (SPTs) que não foram integrados devido à incomunicabilidade das plataformas em que cada um deles foi gerado. Como ação potencial foi sugerida a expansão das relações com o Núcleo de Integração Tecnológica da universidade (NIT), na busca por um sistema integrado de gestão (ERP) para o HU.

Quanto ao descritor D29, que trata dos instrumentos de controle gerencial, a baixa performance deveu-se à não utilização deles. Apesar da realização de cursos e seminários sobre algumas ferramentas como, por exemplo, o Balance Score Card (BSC) e a análise do valor agregado (EVA), não há emprego efetivo delas. Nesse sentido, os pesquisadores sugeriram à decisora uma aproximação com os cursos de Administração, Contabilidade e Economia da universidade. Muitos dos trabalhos de conclusão (TCC) desses cursos se referem a tais ferramentas gerenciais e, em uma relação de parceria, seria possível a realização de um TCC no HU com o objetivo da implantação de um instrumento de controle gerencial.

É importante salientar que se pode proceder diversas análises na fase de recomendações. A análise de sensibilidade pode ser útil quando o decisor achar conveniente mensurar os resultados advindos de uma mudança em determinado parâmetro do modelo. 0 software M-MACBETH, por exemplo, permite realizar a análise de robustez das escalas cardinais bem como a análise de sensibilidade entre as taxas de substituição do modelo.

Outra análise relevante, especificamente para esse modelo construído, é a comparação dos requisitos exigidos para obtenção da certificação previstos na portaria n. 2.400 de 2 de outubro de 2007 (ver seção 2) com os indicadores elaborados neste trabalho (BRASIL, 2007). Em uma analogia vis-à-vis, pode-se inferir que:

0 requisito 1 da portaria é atendido por dois dos quatro descritores do PVF1 - formação profissional e é medido pelos descritores D1 - número de estagiários de Medicina em PSF (Programa de Saúde da Família) e D2 - número de estagiários de Enfermagem em PSF;

0 requisito 11 é contemplado pelo descritor D4 - número de vagas para residência médica em PSF, integrante do PVF1;

0 requisito 111 diz respeito ao cumprimento da legislação sobre condições de ensino e não foi objeto de elaboração de descritores;

0 requisito IV é vislumbrado pelo PFV3 - pesquisa aplicada. Os descritores D9 - número de pesquisas desenvolvidas no HE com foco no SUS e D10 - número de publicações de resultados de pesquisa com foco no SUS compõem esse PVF;

0 requisito $\mathrm{V}$, atendido pelo desempenho do eixo Educação do modelo construído (ver Figura 3), é formado por todos os descritores dos PVF1 - formação profissional, PVF2 - educação permanente e PVF3 - pesquisa aplicada;

Os requisitos $\mathrm{Vl}$ e $\mathrm{VIl}$ são atinentes às exigências previstas na Lei das Diretrizes Curriculares de Educação. Os requisitos VIII e IX dizem respeito à legislação vigente sobre instituições hospitalares. Diante disso não houve necessidade da construção de descritores para tais incisos;

0 requisito $X$ é atendido pelo PVF2 - educação permanente, por meio dos descritores D5 - número de cursos oferecidos para profissionais da rede de atenção básica, D7 - número de servidores do HU com participação em congressos, seminários e simpósios no período de um ano e também pelo PVF1, com o descritor D3 - número de cursos oferecidos para capacitação em PSF;

0 requisito $\mathrm{Xl}$ refere-se ao eixo Atenção à saúde do modelo, composto pelos descritores PVF4 - atenção básica, PVF5 - média complexidade e PVF6 - alta complexidade;

0 requisito XII é demandado pelos descritores D17 - porcentagem de internações de média complexidade SUS, D18 - porcentagem de atendimento ambulatorial de média complexidade SUS, D19 - porcentagem de internações de alta complexidade SUS e D20 porcentagem de atendimento ambulatorial de alta complexidade SUS;

0 requisito $\mathrm{XIII}$ diz respeito aos procedimentos burocráticos de contratação de serviços e conveniados e, assim como o requisito XIV, que se refere à adesão ao Plano Estadual de Assistência a Urgência, não foi operacionalizado no modelo;

Os requisitos $\mathrm{XV}$ e $\mathrm{XV}$ l fazem parte do eixo Humanização do modelo, que engloba descritores dos pontos de vista fundamentais PVF9 - Grupo de Trabalho em Humanização (GTH) e PVF10 - Política de Humanização e Assistência a Saúde (PHAS); e

0 último requisito do artigo sétimo da portaria, inciso XVII, relaciona-se ao PFV8 - gestão operacional, integrante do eixo Gestão do modelo, e tem como um de seus descritores o D29 - uso de instrumentos de controle gerencial. Caracteriza-se como um descritor indireto que demonstra se técnicas atuais de gerência são adotadas e, por conseguinte, a qualificação da gestão.

É importante salientar que o modelo construído não se limita aos incisos do artigo sétimo da portaria n. 2.400 (BRASIL, 2007). Ele procura operacionalizar 
o modelo de avaliação de desempenho dentro da filosofia preconizada pelo SUS, das dimensões da gestão, do ensino e da assistência. 0 que, na percepção da decisora, é mais amplo do que os aspectos tratados na portaria.

Com a finalização da fase de recomendações, encerra-se o desenvolvimento do modelo de apoio à decisão personalizado para a decisora do HU objeto do presente estudo de caso. A intervenção por meio da metodologia de apoio à decisão MCDA, sob a luz do paradigma construtivista, proporcionou a geração de conhecimento sobre o que ter em conta na gestão do hospital para obtenção da certificação como hospital de ensino no âmbito do SUS, como mensurar e qual a situação atual. Esse entendimento passou, então, a servir de base para gerar ações de melhoria e, assim, qualificar melhor o hospital para o alcance do objetivo proposto. Enfatize-se que o modelo e conhecimento construídos refletem as percepções e interpretações pessoais da decisora e que só foi possível construir esse modelo com a efetiva participação da decisora, em todas as fases do processo.

\section{Considerações finais}

0 presente trabalho teve caráter exploratório e descreveu o uso de metodologia multicritério de apoio à decisão (MCDA) como instrumento de intervenção no estudo de caso realizado em um hospital universitário da rede federal de educação, com o objetivo de desenvolver um modelo personalizado de avaliação de desempenho para auxiliar os gestores daquele hospital na identificação, operacionalização e mensuração de critérios que contemplam as metas pactuadas para a obtenção da certificação junto ao MS/SUS. 0 trabalho foi desencadeado em três fases, de forma sistêmica e sistematizada: a fase de estruturação, a fase de avaliação e a fase de recomendações. Os dados para a construção do modelo foram obtidos, em sua grande parte, por meio de entrevistas com a decisora. Complementarmente, alguns dados referentes a aspectos específicos foram obtidos de pesquisas documentais. A abordagem empregada para a análise desses dados foi qualiquantitativa. A lógica de pesquisa foi mista, indutiva, na fase de estruturação, e dedutiva, na fase de recomendações e na de avaliação.

A escolha da MCDA como instrumento de intervenção se deveu à complexidade do contexto e à falta de convicção da decisora e demais atores envolvidos quanto a quais critérios (PVFs) ter em conta e quanto à operacionalização das metas das sete grandes áreas elencadas pelo SUS para a certificação. Nesse sentido, o processo de apoio à decisão permitiu à decisora identificar, organizar e mensurar os aspectos (critérios) que ela considerou relevantes na avaliação do HU para a contratualização das metas pactuadas com o SUS.

0 objetivo geral da pesquisa, que consistiu na construção de um modelo personalizado de avaliação de desempenho para o $\mathrm{HU}$, foi concretizado por meio da Equação 9, que define o perfil global de avaliação para quaisquer possíveis ações que venham a ser julgadas. 0 alcance do objetivo geral foi obtido de forma gradual, à medida que os objetivos específicos do trabalho encadearam-se nas fases de estruturação, avaliação e recomendações.

Sob essa perspectiva, as seguintes ações foram implementadas na fase de estruturação: a identificação dos elementos primários de avaliação; a construção dos conceitos orientados para a ação e o agrupamento desses em clusters; confecção do mapa de relações meios-fins entre os conceitos; transição do mapa de relações meios-fins para uma estrutura hierárquica de valores; e construção das escalas ordinais para os descritores identificados.

Na fase de avaliação ocorreu a transformação das escalas ordinais em escalas cardinais; a construção do modelo de agregação dos critérios; e a representação do perfil de desempenho das ações no modelo construído.

Por fim, na fase de recomendações foi feita a identificação e análise de elementos e aspectos que, no entendimento e segundo os julgamentos de valor da decisora, mereceram ações de aperfeiçoamento. Além disso, foi realizada comparação dos requisitos da portaria interministerial n. 2.400/2007 (BRASIL, 2007), que estabelece as condições para certificação dos hospitais de ensino, com os indicadores elaborados no modelo.

0 modelo construído foi legitimado pela decisora em cada uma das fases de sua construção. Com seu término, a decisora passou a contar com um instrumento formal que oportuniza a comprovação das formas pelas quais o $\mathrm{HU}$ operacionaliza e mensura ações que visam impactar no desempenho das metas exigidas pelo SUS.

Como contribuição do trabalho cita-se, no nível teórico, o detalhamento da fase de estruturação e suas etapas, bem como da fase de avaliação, que viabilizam o entendimento de aspectos específicos da implementação da metodologia. No nível prático, a capacidade da MCDA de gerar entendimento para o decisor, que é participante ativo de todo o processo, e a potencialidade para tratar de cenários complexos (messes com critérios pouco definidos.

As principais limitações do trabalho são a elevada demanda de tempo, devido ao nível de intervenção do estudo de caso, a necessidade de alto grau de 
comprometimento do decisor no processo de pesquisa e a impossibilidade de generalizações a partir do modelo personalizado construído.

Para futuras pesquisas sugere-se a utilização da metodologia MCDA para o desenvolvimento de um modelo de avaliação para a obtenção (ou renovação) da certificação com o SUS em outros dos 46 hospitais integrantes das universidades federais brasileiras. Em outra mão, seria interessante que o mesmo contexto fosse avaliado por outros atores que não a decisora, no caso específico, pelos servidores do hospital.

\section{Referências}

BANA E COSTA, C. A. Três convicções fundamentais na prática do apoio à decisão. Revista Pesquisa Operacional, v. 13, p. 1-12, 1993.

BANA E COSTA, C. A.; VANSNICK, J. C. Uma nova abordagem ao problema de construção de uma função de valor cardinal: MACBETH. Investigação Operacional, v. 15, p. 15-35, 1995

BANA E COSTA, C. A. et al. Decision support systems in action: integrated application in multicriteria decision aid process. European Journal of Operational Research, v. 113, p. 315-335, 1999. http://dx.doi.org/10.1016/ S0377-2217(98)00219-7

BEINAT, E. Multiattribute value functions for environmental management. Amsterdam: Tinbergen Institute Research Series, 1995.

BRASIL. Constituição da República Federativa do Brasil. São Paulo: Atlas, 1988.

BRASIL. Ministério da Saúde. Assessoria de Comunicação Social. Lei $\mathrm{n}^{\circ}$ 8.080, de 19 de setembro de 1990 . Dispõe sobre as condições para a promoção, proteção e recuperação da saúde, a organização e o funcionamento dos serviços correspondentes e dá outras providências. In: BRASIL. Ministério da Saúde. Lei orgânica da saúde. 2. ed. Brasília: Assessoria de Comunicação Social, 1991. p. 7-22.

BRASIL. Ministério da Saúde. Portaria Interministerial no 562 de 12 de maio de 2003. Dispõe sobre a criação da Comissão Interinstitucional com o objetivo de avaliar e diagnosticar a situação dos hospitais universitários no Brasil. Diário Oficial da República Federativa do Brasil, Brasília, DF, maio 2003. Disponível em: <http://dtr2001. saude.gov.br/sas/PORTARIAS/Port2003/GM/GM-562. htm>. Acesso em: 03 jan. 2012.

BRASIL. Ministério da Saúde. Ministério da Educação. Portaria Interministerial MEC/MS n 1.000, de 15 de abril de 2004. Dispõe sobre as condições para certificação dos hospitais de ensino. Diário Oficial da República Federativa do Brasil, Brasília, DF, abr. 2004a. Disponível em: <http://www.femerj.org.br/Boletim/Federal/ Ministerio\%20Saude/GM/2004/Junho/PORTARIA\%20 INTERMINISTERIAL\%20N\%BA\%201000.pdf>. Acesso em: 12 jan. 2012.

BRASIL. Ministério da Saúde. Ministério da Educação. Portaria Interministerial $n^{\circ}$ 1.005/MEC/MS, de 27 de maio de 2004. Dispõe sobre a constituição da comissão de certificação dos hospitais de ensino. Diário Oficial da República Federativa do Brasil, Brasília, DF, 31 maio 2004b. Seção 1, p. 54. Disponível em: <http://
dtr2001.saude.gov.br/sas/P0RTARIAS/Port2004/GM/ GM-1005.htm>. Acesso em: 09 jan. 2012.

BRASIL. Ministério da Saúde. Ministério da Educação. Portaria $n^{\circ} 1.702 / G M$, de 17 de agosto de 2004. Cria o Programa de Reestruturação dos Hospitais de Ensino no âmbito do Sistema Único de Saúde - SUS, e dá outras providências. Diário Oficial da República Federativa do Brasil, Brasília, DF, ago. 2004c. Disponível em: <http://dtr2001.saude. gov.br/sas/PORTARIAS/Port2004/GM/GM-1702.htm>. Acesso em: 03 jan. 2012.

BRASIL. Ministério da Saúde. Portaria $n^{\circ}$ 1.703/GM, de 17 de agosto de 2004. Destina recurso de incentivo à contratualização de Hospitais de Ensino Públicos e Privados, e dá outras providências. Diário Oficial da República Federativa do Brasil, Brasília, DF, ago. 2004d. Disponível em: <http://dtr2001.saude.gov.br/sas/ PORTARIAS/Port2004/GM/GM-1703.htm>. Acesso em: 03 jan. 2012.

BRASIL. Ministério da Saúde. Portaria Interministeria $n^{\circ} 2.352 / G M$, de 26 de outubro de 2004. Regulamenta a alocação dos recursos financeiros destinados ao processo de contratualização constante do Programa de Reestruturação dos Hospitais de Ensino do Ministério da Educação no Sistema Único de Saúde - SUS, e dá outras providências. Diário Oficial da República Federativa do Brasil, Brasília, DF, out. 2004e. Disponível em: <http:// dtr2001.saude.gov.br/sas/PORTARIAS/Port2004/GM/ GM-2352.htm>. Acesso em: 03 jan. 2012.

BRASIL. Ministério da Saúde. Portaria $n^{\circ}$ 2.988, de 22 de novembro de 2006. Dispõe sobre a alteração da composição da comissão interinstitucional constituída pela Portaria $n^{\circ}$ 562, de 12 de maio de 2003. Diário Oficial da República Federativa do Brasil, Brasília, DF, 23 nov. 2006. Disponivel em: <ftp://ftp.saude. sp.gov.br/ftpsessp/bibliote/informe_eletronico/2006/iels. novembro.06/iels223/U_PT-Interm-2988_221106.pdf>. Acesso em: 03 jan. 2012.

BRASIL. Ministério da Saúde. Portaria $n^{\circ}$ 2.400, de 02 de outubro de 2007. Estabelece os requisitos para a certificação dos hospitais de ensino. Diário Oficial da República Federativa do Brasil, Brasília, DF, out. 2007. Disponível em: <http://dtr2001.saude.gov.br/sas/ PORTARIAS/Port2007/GM/GM-2400.htm>. Acesso em: 03 jan. 2012

BRASIL. Ministério da Saúde. Secretaria de Atenção à Saúde. Departamento de Atenção Especializada. Análise do processo de contratualização dos hospitais de ensino e filantrópicos no SUS: dificuldades, perspectivas e propostas. Brasília: Editora do Ministério da Saúde, 2010.

CHECKLAND, P.; SCHOLES, J. Soft Systems Methodology in Action: include a 30 years retrospective. New York: Wiley, 1999.

CORREA, E. C. Construção de um modelo multicritério de apoio ao processo decisório. 1996. 247 f. Dissertação (Mestrado em Engenharia de Produção)-Universidade Federal de Santa Catarina, Florianópolis, 1996.

COSTA, M.; MOTA, J.; FIGUEIRED0, R. A nova dinâmica institucional do hospital das clínicas da UFMG: o projeto de unidades funcionais e a contratualização com o SUS/ BH. Revista de Medicina de Minas Gerais, v. 19, n. 3 , p. 269-275, 2009.

EDEN, C. Cognitive mapping. European Journal of Operational Research, v. 36, p. 01-13, 1988.

ENSSLIN, L.; MONTIBELLER, G. N.; NORONHA, S. M. Apoio à Decisão: metodologias para estruturação de problemas 
e avaliação multicritério de alternativas. Florianópolis: Insular, 2001.

ENSSLIN, L. et al. Avaliação de desempenho de empresas terceirizadas com o uso da metodologia multicritério de apoio à decisão - construtivista. Pesquisa Operacional, v. 30, p. 125-152, 2010.

KEENEY, R. L. Value-focused thinking: a path to creative decision making. London: Harvard University Press, 1992.

KEENEY, R. L.; RAIFFA, H. Decision with multiple objectives: Preferences and Value Trade-offs. New York: Wiley, 1993.

LONGARAY, A. A. Estruturação de situações problemáticas baseada na integração da Soft Systems Methodology e da MCDA Construtivista. 2004. 396 f. Tese (Doutorado em Engenharia de Produção)-Universidade Federal de Santa Catarina, Florianópolis, 2004.

MACHADO, S.; KUCHENBECKER, R. Desafios e perspectivas futuras dos hospitais universitários no Brasil. Ciência \& Saúde Coletiva, v. 12, n. 4, p. 871-877, 2007. http:// dx.doi.org/10.1590/S1413-81232007000400009

ROBERTS, F. Measurement Theory. In: ENCYCLOPEDIA of Mathematics and lts Applications. New York: AddisonWesley Publishing Company, 1979.
ROESCH, S. M. Projeto de estágio e de pesquisa em administração. São Paulo: Atlas, 2005.

ROSENHEAD, J. Rational analysis for a problematic world: problems structuring methods for complexity, uncertainty, and conflict. Chichester: John Wiley and Sons, 1989.

ROY, B. Multicriteria Methodology for Decision Aiding. Dordrecht: Kluwer Academic Publishers, 1996.

TRIVIÑOS, A. Introdução à pesquisa em ciências sociais. São Paulo: Atlas, 1995.

VECINA NETO, G.; MALIK, A. M. Tendências na assistência hospitalar. Ciência \& Saúde Coletiva, v. 12, n. 4, p. 825839, 2007.

YIN, R. K. Estudo de caso: planejamento e métodos. Porto Alegre: Bookmann, 2001.

\section{Agradecimentos}

Agradecemos à FAPERGS pelo apoio financeiro (processo ARD 05/1696.4) e aos revisores anônimos pelos úteis comentários e sugestões enriquecedoras do trabalho.

\title{
The usage of MCDA in identification and measurement of criteria performance for certification of public teaching hospitals in Brazil
}

\begin{abstract}
The public health system management in Brazil has undergone a certain amount of restructuring over the past years. One consequence of the restructuring was the establishment of a new relationship between the Ministry of Health (MS) and the Ministry of Education (MEC) regarding the funding of University Hospitals of Federal Universities. Therefore, the Brazilian Ministry of Health has implemented the certification process of University Hospitals - a set of goals to be met concerning financial, management and education processes, as well as the assistance model to be adopted. This article presents the use of Multi Criteria Decision Analysis to support the development of a model aimed at assisting managers of a university hospital in assessing institutional performance, so that their goals jointly agreed between the MS/MEC can be met and certification is obtained. The case study was conducted within a hospital of the federal network of education in Brazil.
\end{abstract}

\section{Keywords}

Multi Criteria Decision Analysis. Public Health. University Hospitals. 